\title{
A Psicologia da Educação nos cursos de graduação em Psicologia de Belo Horizonte/MG
}

\author{
Rita de Cássia Vieira \\ Universidade Federal de Minas Gerais - MG \\ Ellen Rose Fernandes Figueiredo \\ Universidade Federal de Minas Gerais - MG \\ Laís Gonçalves de Souza \\ Universidade Federal de Minas Gerais - MG \\ Marina Castana Fenner \\ Universidade Federal de Minas Gerais - MG
}

\begin{abstract}
Resumo
O binômio formação/atuação profissional do psicólogo educacional/escolar é o que se discute neste texto. O debate é feito com base numa pesquisa que investigou o processo de formação desenvolvido nos cursos de Psicologia das instituições de ensino superior de Belo Horizonte/ MG. O método utilizou-se de um conjunto de procedimentos: entrevistas com coordenadores de curso e professores da área em questão; análise de matrizes curriculares, ementas e planos de ensino; buscas nos sites das instituições estudadas; pesquisa bibliográfica. Os dados foram analisados com base na análise de conteúdo. Os resultados, apesar de revelarem um processo de formação em mudança, também apontaram permanências e desafios que vêm sendo alvo de intenso debate na área da psicologia educacional/escolar.
\end{abstract}

Palavras-chave: Formação do psicólogo, atuação do psicólogo, psicologia escolar.

\section{Educational Psychology in Belo Horizonte's undergraduate programs}

\begin{abstract}
In this work we discuss the binary training/professional performance of educational psychologist. The debate is based on a research on the process developed in the undergratuate Psychology programs of Belo Horizonte/MG. The method used was a series of procedures: interviews with course coordinators and teachers of the area, analysis of curricular matrices, lesson plans and summaries, search the websites of the institutions studied and literature. We analyzed data based on content analysis. The results, although revealing a formation process of change, also pointed out the continuities and challenges which have been targets of intense debate in the field of educational psychology.
\end{abstract}

Keywords: Psychologist education, psychologist performance, school psychology.

\section{La psicología de la educación en cursos de Pre Grado en Psicología de Belo Horizonte/MG}

\begin{abstract}
Resumen
El binomio formación/actuación profesional del psicólogo educacional/escolar es el tema discutido en este texto. El debate tiene por base una investigación del proceso de formación desarrollado en los cursos de Psicología de instituciones de enseñanza superior de Belo Horizonte/MG. El método se sirvió de un conjunto de procedimientos: entrevistas con coordinadores de curso y profesores del área en cuestión; análisis de matrices curriculares, programas y planes de enseñanza; buscas en los sitios de las instituciones estudiadas; investigación bibliográfica. Los datos se analizaron sobre la base del análisis de contenido. Los resultados, al paso que revelan un proceso de formación en transformación, también señalaron permanencias y desafíos que han sido objetos de intenso debate en el área de la psicología educacional/escolar.

Palabras clave: Formación del psicólogo, actuación del psicólogo, psicología escolar.
\end{abstract}




\section{Introdução}

Uma das profissões que mais crescem, estudam e pensam seus rumos no Brasil (Yamamoto \& Costa, 2010), a profissão de psicólogo é também aquela que lida com um quadro de sérias dificuldades e desafios no que se refere à formação. Evidenciam-se deficiências generalizadas no processo formativo, tanto no âmbito teórico quanto no da prática (Campos, 2007; Marinho-Araújo, 2009; Rodrigues, Itaborahy, Pereira, \& Gonçalves, 2008, dentre outros).

A despeito de mudanças já visíveis, persiste na formação em Psicologia a tendência a um modelo clínico, fundamentado em uma visão curativa e individualizada dos processos psicológicos. Embora a formação e a atuação sejam dimensões inseparáveis e devam sempre ser pensadas em termos de articulação, o que se constata é que esse viés da formação tem implicações diversas. A significativa distância entre o que se aprende nos cursos de graduação e as demandas apresentadas pelo mercado de trabalho na atualidade destaca-se como uma dessas decorrências.

No âmbito da Psicologia da Educação, os desafios se acentuam quando se constata a perda de espaço do psicólogo nesse campo, com uma expressiva queda no percentual dos que atuam na área, em instituições educacionais ou em escolas (Bastos \& Gondim, 2010). O estudante de Psicologia desconhece as possibilidades de atuação nesse âmbito (Souza Filho, Oliveira, \& Lima, 2006), e, ao inserir-se como psicólogo nesse campo, passa a atuar de forma descontextualizada, em conformidade com uma crítica que vem sendo realizada há décadas. Essa crítica, inaugurada com os clássicos textos de Patto (1984, 1991), denuncia, em linhas gerais, a existência de práticas desenvolvidas pelos profissionais da Psicologia nos espaços educativos/ escolares de forma simplista, reducionista, excludente e culturalmente descontextualizada.

Sem desconsiderar a legitimidade de muitas situações expostas por essa vertente crítica, o estudo de Vieira (2012) contribuiu no sentido de indicar que esse ponto de vista é passível de ser contestado. Nesse estudo a autora apresenta um exemplo no qual, apesar de num tempo e condições sociais adversas, psicólogos atuaram de forma a incluir em suas práticas uma preocupação cada vez maior com a interpretação sociocultural dos processos psicológicos e com a inclusão escolar e social dos sujeitos atendidos. A autora também comprova que apenas uma sólida formação teórico-técnica, adquirida com base numa associação entre ensino, pesquisa e extensão, é capaz de oferecer ao psicólogo condições de refletir e desenvolver práticas críticas (Meira \& Antunes, 2003) alinhadas com as atuais demandas sociais brasileiras e que favoreçam mudanças nos processos educativos.

A despeito de toda a sua complexidade, a educação, com os diversos contextos onde ela se dá, além da escola, é um espaço privilegiado de reflexão e crítica, uma área vital para fomentar processos de mudança individuais, grupais e sociais. Assim, é preciso que o psicólogo se qualifique para enfrentar as diferentes demandas que Ihe são dirigidas nesses contextos. Sua formação deve se pautar por uma articulação entre teoria, pesquisa e prática, e propiciar reflexões sobre as implicações políticas, culturais e ideológicas do fazer psicológico. Além disso, deve também favorecer o encaminhamento de processos de mudança onde estes se fizerem necessários, buscando soluções para um tempo em que vivemos "um desafio perene: integrar pesquisa científica, Psicologia e o que caracteriza o Brasil" (Botomé, 2007, p. 30).

Integrando as estruturas curriculares dos cursos de graduação em Psicologia, as disciplinas que apresentam vinculação com o âmbito da Educação deveriam se propor a se constituir em espaços amplos de interlocução entre esses dois campos disciplinares. Nesse processo, elas deveriam promover a indispensável articulação entre o conhecimento teórico obtido em sala de aula e as intrincadas situações que os contextos educativos irão apresentar ao futuro psicólogo. Não obstante, como observa Larocca (2000), percebe-se nesses currículos uma perspectiva que ignora a inter-relação dialética existente entre saber e fazer, entre teoria e prática, do que decorre a necessidade de resgatar a práxis "como trabalho vivo, movimento dialético entre ação e reflexão" (Larocca, 2000, p. 64).

Nessa perspectiva, ao focalizar as dimensões ensino e psicologia da educação, algumas perguntas são centrais: como o saber constituído por esse campo vem sendo ensinado nos cursos de Psicologia? Esse ensino tem contribuído para a prática do psicólogo? Foi a partir dessas questões que se pensou em investigar o processo de formação que vem sendo desenvolvido nos cursos de Psicologia nas instituições de ensino superior de Belo Horizonte, com foco na área da Psicologia da Educação e nas disciplinas afins a essa área. Para tanto, foram investigados todos os cursos de graduação em Psicologia ofertados na capital mineira. A pesquisa partiu da hipótese de que a inexistência de uma estrutura curricular equilibrada, que trate de forma igualitária os campos do saber envolvidos na constituição da ciência psicológica, assim como a forma de propor e operacionalizar as disciplinas relacionadas à Psicologia e à Educação, os estágios - enfim, toda a estruturação do curso nessa área - esteja contribuindo significativamente para legitimar as práticas que ainda hoje vêm sendo criticadas.

\section{Método}

Foi realizada ampla revisão bibliográfica que englobou diversos aspectos relativos à formação e à atuação do psicólogo no âmbito da Educação.

A pesquisa de campo focalizou todas as instituições de ensino superior belo-horizontinas que oferecem graduação em Psicologia, num total de 08 (oito), sendo uma pública e 07 (sete) privadas, conforme mostra a tabela 1.

Foram entrevistados todos os coordenadores dos cursos e mais 14 (quatorze) professores que lecionavam 
Tabela 1. IES e cursos de psicologia da cidade de Belo Horizonte, participantes da pesquisa.

\begin{tabular}{|c|l|l|c|c|}
\hline & IES & $\begin{array}{l}\text { Identificaçãol } \\
\text { Ano de inicio do curso }\end{array}$ & $\begin{array}{c}\text { Carga } \\
\text { horária }\end{array}$ & $\begin{array}{c}\text { Carga horária das disciplinas } \\
\text { afins à área da educação }\end{array}$ \\
\hline $\mathbf{1}$ & FCMMG & $\begin{array}{l}\text { Faculdade de Ciências } \\
\text { Médicas de Minas Gerais } \\
(2009)\end{array}$ & $4880 \mathrm{~h}$ & $220 \mathrm{~h}$ \\
\hline $\mathbf{2}$ & FEAD-MG & $\begin{array}{l}\text { Faculdade de Estudos } \\
\text { Administrativos de Minas } \\
\text { Gerais (2005) }\end{array}$ & $4000 \mathrm{~h}$ & $360 \mathrm{~h}$ \\
\hline $\mathbf{3}$ & FPAS & $\begin{array}{l}\text { Faculdade Pitágoras de } \\
\text { Belo Horizonte (2005) }\end{array}$ & $4050 \mathrm{~h}$ & $30 \mathrm{~h}$ \\
\hline $\mathbf{4}$ & FUMEC & $\begin{array}{l}\text { Universidade FUMEC } \\
(1972)\end{array}$ & $4000 \mathrm{~h}$ & $324 \mathrm{~h}$ \\
\hline $\mathbf{5}$ & NP & $\begin{array}{l}\text { Centro Universitário Newton } \\
\text { Paiva }\end{array}$ & $4100 \mathrm{~h}$ & $108 \mathrm{~h}$ \\
\hline $\mathbf{6}$ & $\begin{array}{l}\text { Campus Coração } \\
\text { Eucarístico }\end{array}$ & $\begin{array}{l}\text { Pontif́cia Universidade } \\
\text { Católica de Minas Gerais } \\
(1959)\end{array}$ & $4100 \mathrm{~h}$ & -------- \\
\hline $\mathbf{6}$ & $\begin{array}{l}\text { PUC Minas } \\
\text { Campus São Gabriel }\end{array}$ & $\begin{array}{l}\text { Pontifícia Universidade } \\
\text { Católica de Minas Gerais } \\
(2000)\end{array}$ & $4100 \mathrm{~h}$ & $384 \mathrm{~h}$ \\
\hline $\mathbf{7}$ & UFMG & $\begin{array}{l}\text { Universidade Federal de } \\
\text { Minas Gerais (1963) }\end{array}$ & $4050 \mathrm{~h}$ & $300 \mathrm{~h}$ \\
\hline $\mathbf{8}$ & UNA & Centro Universitário UNA & $4760 \mathrm{~h}$ & $308 \mathrm{~h}$ \\
\hline & 08 IES & 09 cursos & ------ & ------ \\
\hline
\end{tabular}

disciplinas da área da psicologia da educação e afins ${ }^{1}$. Esses sujeitos foram inicialmente contatados via e-mail e/ou telefone e convidados por escrito a participar da pesquisa, após leitura e assinatura do TCLE (Termo de Consentimento Livre e Esclarecido).

Como principal instrumento de coleta de dados, optou-se nesse estudo pela realização de entrevistas individuais semiestruturadas. Em sua maioria, essas entrevistas foram realizadas pessoalmente, gravadas e transcritas em sua literalidade. Por motivos operacionais, algumas delas foram encaminhadas à equipe de pesquisa via correio eletrônico.

1 Neste estudo, ao nos referirmos à área da Psicologia da Educação, não estamos nos referindo somente às disciplinas tradicionalmente denominadas "Psicologia da Educação" e "Psicologia Escolar", mas também a outras disciplinas correlatas - aqui denominadas disciplinas afins. Estas, no decorrer das entrevistas com os coordenadores, foram por eles indicadas como disciplinas em que eram trabalhados conteúdos relacionados à interface Psicologia e Educação. Nesse grupo encontram-se, por exemplo, disciplinas como "Processos Psicológicos Básicos" e "Desenvolvimento Humano", dentre outras, consideradas como disciplinas de formação geral. Elas concentram-se nos períodos iniciais dos cursos, ao passo que as disciplinas específicas estão inseridas a partir do sexto período.
Com o objetivo de se construir primeiramente uma visão global dos cursos, os coordenadores foram entrevistados em primeiro lugar. Para eles, foi utilizado um roteiro que privilegiou os seguintes aspectos: 1. Currículos (estrutura curricular atual do curso / ênfases / matrizes teóricas enfatizadas / mudanças curriculares / implicações das mudanças curriculares no processo de formação do psicólogo / articulação ensino-pesquisa-extensão na formação do psicólogo); 2. Psicologia da Educação (implicações quantitativas e qualitativas das mudanças curriculares no ensino de psicologia da educação / disciplinas da área / articulação ensino-pesquisa-extensão na área); 3. Mudanças necessárias para uma formação de qualidade na área em estudo.

Para os professores das disciplinas da área e afins, o roteiro da entrevista buscou avaliar preferencialmente as seguintes temáticas: 1. Disciplina (encaminhamento / carga horária / conteúdos ministrados); 2. Receptividade dos alunos; 3. Psicologia da Educação (formação do aluno para atuar na área).

Complementarmente, foram recolhidas e analisadas matrizes curriculares vigentes dos cursos, ementas e planos de ensino. Foram realizadas ainda pesquisas nos sites das 
instituições com o intuito de se obter o maior número possível de dados sobre a temática investigada.

Os dados coletados na fase documental e empírica da pesquisa foram analisados com base na análise de conteúdo (Bardin, 1979; Franco, 2005).

\section{Resultados e discussão}

Em Minas Gerais, mais especificamente em Belo Horizonte, os cursos de formação de psicólogos foram iniciados no ano de 1959. Atualmente, oito instituições ofertam o curso de Psicologia, e o curso mais recente foi implantado em 2009. No total, são ofertadas anualmente 1.484 vagas, distribuídas entre essas instituições em turnos diurnos e noturnos. Cada curso gira em torno de uma carga horária mínima de 4.220 horas (MEC, 2011), conforme anteriormente mostrado na tabela 1.

A maioria desses cursos vem passando por mudanças em sua estrutura curricular, em decorrência da Resolução $n^{\circ}$. 8, de 07 de maio de 2004 (MEC, 2004), que instituiu as diretrizes curriculares nacionais para a graduação em Psicologia, em substituição ao currículo mínimo de 1962. As novas diretrizes estabeleceram um núcleo comum de formação em Psicologia - definido por um conjunto de competências, habilidades e conhecimentos - e propuseram a criação de ênfases curriculares, com o intuito de superar o dualismo ente formação generalista e especialista (Brasileiro \& Souza, 2010). Dessa forma, durante a graduação, uma parte da formação é destinada ao desenvolvimento de competências e habilidades desse núcleo comum e outra parte ao desenvolvimento de repertórios referentes às ênfases, que são escolhidas pelas próprias instituições. Essa escolha é feita de acordo com as especificidades e necessidades regionais de formação, concentrando os estudos e estágios em algum domínio da Psicologia (MEC/CNE/CES, Parecer 0062/2004).

As ênfases curriculares adotadas pelos cursos de Psicologia estudados concentram-se em três áreas tradicionais de atuação do psicólogo: a organizacional, a clínica e a de saúde. Esses dados coincidem com aqueles obtidos na pesquisa sobre a profissão do psicólogo no Brasil realizada pelo Grupo de Trabalho Psicologia, Organizações e TrabaIho da Associação Nacional de Pesquisa e Pós-Graduação em Psicologia entre 2006 e 2008 e publicada recentemente (Bastos \& Gondim, 2010). De acordo com esse estudo, a principal área de inserção dos psicólogos brasileiros continua a ser a clínica, vindo em segundo lugar a área da saúde, e em terceiro, a organizacional/trabalho.

Chama a atenção o fato de que, dentre as instituições pesquisadas, somente uma oferece ênfase à área da Educação. Essa oferta se alinha com o quadro nacional apresentado pelo recente estudo de Bastos e Gondim (2010), que constatou uma redução significativa do número de profissionais atuando na área. No que se refere às ênfases, a estruturação dos cursos estudados estaria, então, seguindo uma lógica mercadológica e preparando melhor os psicólogos para atuarem em campos de trabalho onde eles estariam sendo mais demandados; no entanto se faz necessária outra ótica: a mesma pesquisa (Bastos \& Gondim, 2010) observa que a fragilidade de condições do mercado leva o psicólogo a transitar por duas, três e às vezes até mais áreas de atuação. Esse fato implica em se pensar numa certa fluidez entre os limites teórico-práticos de algumas áreas, o que certamente recairia numa perspectiva de formação abrangente que permitiria ao psicólogo realizar com competência seu trânsito entre uma área e outra. Antes de tudo, porém, uma discussão importante para o processo formativo, como propõem Yamamoto e Costa (2010), seria uma rediscussão do tradicional conceito de área.

Ao atentar pelas exigências sociais da atualidade, essa perspectiva parece ter sido considerada pelas instituições de Belo Horizonte ao proporem as suas ênfases. De acordo com os coordenadores de curso entrevistados, essa escolha se deu em função, principalmente: (1) da tradição do curso; (2) das características da instituição em questão, do corpo docente e dos programas de pós-graduação (3) dos estágios e projetos de extensão preexistentes; e (4) das demandas sociais.

(...) O curso de Psicologia daqui sempre teve uma tradição na clínica, uma clínica mais particular. Então, historicamente é importante ter uma ênfase em Psicologia Clínica, embora hoje ela não é voltada para consultório somente, ela tem uma visão ampliada também. E com a mudança da Psicologia ao longo do tempo, né, foi necessário, claro que foi, é, outras áreas importantes, então a gente fez essa segunda ênfase, que é chamada Psicologia, Organizações e Sociedade, onde é mais uma Psicologia aplicada, ligada às diferentes organizações e instituições. Então é para acompanhar realmente as mudanças na sociedade.

A relação entre ênfase e estágio precisa ser destacada. É sabido que os estágios exercem papel fundamental na formação de qualquer profissional, constituindo-se nos primeiros contatos dos alunos com a prática profissional. São essas experiências que colocam o estudante diante de situações capazes de promover reflexões sobre a sua profissão e sua preparação profissional, além de fortalecer a identidade do profissional na área de escolha (Sousa, 2004). O estágio na vida acadêmica é a oportunidade que o aluno tem de se distanciar dos riscos de ter na sua atuação atitudes alienadas, baseadas apenas em conhecimentos teóricos e abstratos (Novaes, 2008), percepção que é visível no relato dos professores, como se vê no exemplo abaixo:

A formação do psicólogo é muito baseada em informação, informar na sala de aula sobre teorias, você tem quantidade de informações muito grande que são passadas... De modo que a pessoa aprende pouco a como fazer, a como usar, como aplicar, como analisar, como lê. O como é pouco trabalhado, mas o como é muito importante na hora da prática profissional. 
Foi provavelmente pensando na necessidade de se articular o saber com o fazer no processo de formação que as novas diretrizes (MEC, 2004) determinam que os estágios supervisionados sejam relacionados à ênfase escolhida. Dada a estruturação dos cursos de Belo Horizonte no que se refere às ênfases, é de se supor, inicialmente, que a formação dos psicólogos para atuar na área educacional tende a ficar ainda mais comprometida, uma vez que os estágios nessa área, em cursos com outras ênfases, ficaram restritos apenas aos estágios básicos do núcleo comum:

O que acontece hoje - estágios básicos - nós temos na área educacional também, mas os estágios quando entra no $10^{\circ}$ período são mais específicos das ênfases, eles não têm braço na educacional, então nesse ponto, o lado educacional fica mais fragilizado.

Por outro lado, algumas denominações de ênfases merecem ser destacadas, a exemplo de "Psicologia e intervenções nas instituições e organizações", "Psicologia e processos da saúde", "Psicologia e processos de gestão". Numa análise bastante superficial, a julgar exclusivamente por essa nomenclatura, pode-se supor que os conteúdos apresentados pelas disciplinas que as compõem também estariam alinhadas com a necessidade apontada por Bastos e Gondim (2010) de rediscutir o conceito de área como espaço delimitado de conhecimentos específicos.

Provavelmente, foi pensando nessa direção que todos os coordenadores entrevistados afirmaram que a atual estrutura curricular adotada trata de forma equilibrada os diferentes saberes e áreas de atuação do psicólogo. Para tanto o Ministério da Educação - MEC (2004) advoga que "O subconjunto de competências definido como escopo de cada ênfase deverá ser suficientemente abrangente para não configurar uma especialização em uma prática, procedimento ou local de atuação do psicólogo". Embora não seja esta a proposta do MEC, percebe-se que as ênfases curriculares têm restringido as opções dos alunos, que acabam por concentrar seus estudos em campos de atuação específicos, que na maioria das vezes são as tradicionais áreas da clínica, saúde e organizações. Isso provavelmente está acontecendo devido às dificuldades que as instituições têm encontrado para romper com o modelo de formação que vem sendo oferecido. Os próprios coordenadores de curso advertiram que a escolha das ênfases foi pautada na estrutura que o curso já possuía - formação do corpo docente e núcleos de pesquisas e estágios já existentes.

Uma das coordenadoras (C6) mencionou que essa nova proposta curricular do MEC tem um ar mais contemporâneo em relação às propostas anteriores, uma vez que amplia a ideia de formação para além da sala de aula. Como exemplo disso ela cita as Atividades Complementares de Graduação (ACG's), as quais ela supõe que incentivam a participação dos alunos em atividades extraclasse - como projetos de pesquisa e extensão, eventos científicos e grupos de estudo - visto que contabilizam créditos ao currículo.
Apesar de bem recebida, a operacionalização da troca curricular tem sido um desafio para as instituições formadoras, como observa uma das entrevistadas:

(...) operacionalizar um currículo novo não é fácil. É muito complicado. Ao mesmo tempo nós temos correndo um outro em paralelo, então eu tenho dois currículos. Na hora que eu monto horários eu tenho que pensar em dois currículos.

Esses desafios referentes à implantação das novas diretrizes curriculares também foram abordados pelo coordenador e pelos professores do curso de psicologia da Universidade Federal de Rondônia (UNIR) no trabalho de Brasileiro e Souza (2010). Embora reconheçam as contribuições das diretrizes de 2004, os profissionais entrevistados nessa investigação enfatizam as dificuldades em definir as ênfases e em articular os conteúdos teóricos e práticos nos períodos iniciais, principalmente pelo fato de a instituição ter um quadro reduzido de professores.

Uma das coordenadoras das IESs de Belo Horizonte pontuou que, embora julgue necessário atualizar o currículo, a proposta de uma formação generalista é mais interessante. Ela também mencionou que tem encontrado várias dificuldades em encaminhar essas mudanças, principalmente por se tratar de uma instituição de ensino particular, em que as alterações se refletem diretamente nas finanças da faculdade. Segundo ela, a questão das ênfases tem restringido a oferta de disciplinas, o que tem causado descontentamento entre os alunos; porém, para ela, essa dificuldade tem sido sanada quando os estudantes ingressam no campo de estágio, que é bastante amplo e diversificado.

A análise das matrizes curriculares dos cursos também evidenciou esse desafio relativo à oferta de disciplinas específicas das ênfases, a qual se apresentou bastante precária. Os estágios específicos de cada ênfase estão bem delimitados nas oito instituições pesquisadas e iniciam-se, na maioria dos cursos, entre o oitavo e o nono período. Em quatro das nove matrizes curriculares investigadas não se encontrou distinção entre essas disciplinas específicas, diferentemente do verificado nos estágios. Das cinco instituições que ofertam disciplinas específicas da ênfase, apenas uma oferta essas disciplinas no décimo período e uma oferece apenas uma disciplina no oitavo e nono período e duas no décimo. Em apenas três instituições é ofertada mais de uma disciplina específica para cada ênfase em mais de um período.

Após as mudanças curriculares, o espaço destinado às disciplinas da interface Psicologia e Educação permaneceu o mesmo em sete cursos investigados, sendo que em um desses cursos a carga horária das disciplinas foi reduzida. Não obstante, cumpre ressaltar que entre essas instituições o número de disciplinas relacionadas à área da Educação varia bastante, de modo que há cursos que ofertam apenas uma disciplina, enquanto outros ofertam seis. Dos dois cursos restantes, um não teve mudança curricular, pelo fato de ter sido criado em 2009 e já em consonância com as 
novas diretrizes curriculares do MEC, e o outro aumentou o número de disciplinas relacionadas à área.

Chama a atenção o fato de que um desses cursos enfatizava os processos educacionais, ênfase que foi extinta na última modificação de currículo, devido à falta de procura dos alunos. Não obstante, a coordenadora do curso ressaltou que essa alteração foi importante para a área da Educação, uma vez que as disciplinas da ênfase foram todas diluídas no núcleo de formação comum. A extinção dessa ênfase muito possivelmente está vinculada ao desconhecimento dos estudantes acerca das possibilidades de atuação no âmbito da educação, fato já comprovado por várias pesquisas (Asbahr, Martins \& Mazzolini, 2011; Correia, Lima, \& Araújo, 2001; Souza Filho e cols., 2006; Vieira, 2012, dentre outros).

Como já mencionado, essas disciplinas listadas por coordenadores de curso de professores englobam: (1) disciplinas específicas na interface da Psicologia com a Educação; e (2) disciplinas de formação geral que abarcam temas relacionados à Educação. Dentro do primeiro grupo foram incluídas as disciplinas "Psicologia e Educação" e "Psicologia Escolar", e no segundo, o das disciplinas afins, encontram-se disciplinas como "Processos Psicológicos Básicos" e "Desenvolvimento Humano", entre outras. As disciplinas de formação geral concentram-se nos períodos iniciais, ao passo que as disciplinas específicas estão inseridas na grade a partir do sexto período.

Essa forma de estruturação do curso pode dificultar a articulação entre os saberes durante a graduação. Se por um lado as disciplinas específicas da área da educação estão próximas do momento em que o aluno inicia seus estágios, por outro elas ficam isoladas das demais disciplinas afins a essa área. Outra implicação é que isso também pode fazer com que o aluno se interesse pelas áreas que, cronologicamente, são apresentadas por primeiro no curso.

No que diz respeito à carga horária destinada às disciplinas da área em estudo, nove dos quatorze professores entrevistados consideraram-na suficiente para ministrar os conteúdos da ementa. Esses professores afirmaram que isto só é possível porque se pode articular o conteúdo da sua disciplina com o de outras e, quando isso não ocorre, é necessário reduzir os conteúdos ou fazer outros ajustes para conseguir atingir a proposta.

Isso se comprova também na fala daqueles professores que consideraram a carga horária insuficiente ( $P 1$; P5; P7.2 e P8.2), quando apontam dificuldade em articular o conteúdo com outras disciplinas e a necessidade de extrapolar a carga horária para atender ao objetivo da matéria:

Eu acho que se o resto do curso, de alguma forma trouxesse as articulações dessa disciplina pra uma reflexão constante, talvez a carga horária fosse suficiente. Mas se você for pensar que às vezes se quebra, e às vezes vai ser retomado só num momento muito posterior, eu acho que aí é insuficiente (...).

Esses dados demonstram a transdisciplinaridade como um imperativo na educação contemporânea. Mais do que necessária do ponto de vista operacional, a transdiscipli- naridade, de acordo com Santos (2008), permite uma compreensão mais ampliada acerca da realidade, sem romper com a ideia de disciplina, visto que a principal característica dessa tendência é a articulação entre as diferentes áreas do conhecimento. Santos (2008) ressalta ainda que o grande desafio desse olhar transdiciplinar é percorrer os diferentes saberes sem hierarquizá-los.

Essa proposta transdisciplinar se conecta com as proposições apresentadas pelo paradigma crítico-reflexivo em educação (Larocca, 2000), que, entre outros aspectos, aponta a necessidade de formar sujeitos críticos e com condições de refletir constantemente sobre suas práticas, vinculá-las aos seus conhecimentos teóricos e, a partir daí, fazer propostas que se traduzam em transformações nos processos educativos e sociais. Formar sujeitos socioculturais capazes de articular o conhecimento teórico obtido em sala de aula com as intrincadas situações que os contextos educativos irão lhes apresentar seria resgatar a práxis "como trabalho vivo, movimento dialético entre ação e reflexão" (Larocca, 2000, p. 64).

Ao que tudo indica, as diretrizes curriculares de 2004 se pautam por uma formação baseada nessa nova forma de conceber o mundo; contudo, como o campo da Psicologia é uma área que, desde o seu nascimento, vive em permanente crise, em decorrência da sua ampla diversidade teórica e metodológica (Figueiredo, 2009), promover uma formação que perpasse pelos diferentes campos do saber psicológico é um desafio enorme para as instituições que ofertam o curso.

Quanto à receptividade dos alunos às disciplinas da área, a opinião dos professores apresentou-se bastante dividida. Cinco dos entrevistados disseram que as disciplinas são bem recebidas, sendo que desses cinco, três ministram disciplinas de desenvolvimento humano. Esse destaque dado às disciplinas de desenvolvimento humano no âmbito da Educação também foi constatado em um estudo desenvolvido por Senna e Almeida (2007) com psicólogos da rede pública de ensino do Distrito Federal. Nessa pesquisa, a maioria dos entrevistados considerou a formação teórica como a que mais contribuía para sua atuação no contexto escolar, sobretudo no que se refere aos conteúdos relacionados à Psicologia do Desenvolvimento e à Psicologia da Infância. Apesar de essas disciplinas tratarem dos processos de desenvolvimento e aprendizagem, as autoras chamam a atenção para o fato de que elas, isoladamente, não fornecem os elementos necessários para a atuação do psicólogo na escola.

Este mesmo estudo (Senna \& Almeida, 2007) abordou aspectos da formação e atuação dos psicólogos para atuarem na área da educação, investigando, sobretudo, a postura adotada por esses profissionais para suprir as lacunas deixadas durante a graduação. Por isso, um dado importante encontrado nesse estudo foi que a maioria dos psicólogos entrevistados buscava respaldo nas teorias clínicas para atuarem no contexto escolar. Um trabalho realizado com psicólogos da rede particular de ensino de Uberlândia, MG (Souza, Ribeiro, \& Silva, 2011) também constatou que vários desses profissionais combinavam diferentes teorias 
psicológicas para intervirem nas escolas, muitas vezes partindo de pressupostos epistemológicos contraditórios.

Ambos os estudos evidenciaram o fato de os psicólogos não terem acesso a um conhecimento mais consistente sobre o campo teórico e prático da Psicologia da Educação durante a graduação. Souza e cols. (2011) observam que a atuação deficiente ocorre não apenas pelo fato de os cursos de Psicologia não oferecerem uma formação sólida na área, mas também devido ao desinteresse dos estudantes pelo campo da educação. As autoras afirmam ainda que o interesse pela área surge à medida que os profissionais se inserem no mercado de trabalho e finalizam apontando "a necessidade de um maior investimento das instituições formadoras e dos profissionais atuantes, para ampliar o campo de atuação do psicólogo escolar e possibilitar práticas emancipatórias" (Souza e cols., 2011, p.53).

No presente estudo, seis dos catorze professores entrevistados, ou seja, praticamente $50 \%$, alegaram que é necessário fazer um esforço inicial para que os alunos se deixem envolver pela matéria. Na tentativa de explicar esse aparente desinteresse dos alunos pelas disciplinas relacionadas à área da educação, alguns professores apontaram as seguintes causas: (1) muitos alunos acham que a área de atuação do psicólogo da Educação se restringe à escola e à educação infantil; (2) há a crença de que as disciplinas específicas da interface Psicologia e Educação repetem os conteúdos de Psicologia Genética, vistos em Desenvolvimento Humano; e (3) os alunos possuem outras áreas de interesse, sobretudo a da clínica:

Percebo que, a princípio, existe uma resistência às disciplinas situadas na interface da Psicologia e Educação. A principal queixa é relativa a uma repetição de conteúdo no campo das Psicologias Genéticas, ou seja, muitas vezes os alunos se queixam de que já estudaram muito Piaget ou Vigotski.

Os professores por nós entrevistados apresentaram diferentes maneiras de encaminhar suas disciplinas: uns preferem adotar uma perspectiva crítica, promovendo discussões ao longo do semestre acerca do papel do psicólogo no espaço educacional; outros optam por apresentar a diversidade teórica e as inúmeras possibilidades de atuação no campo da Educação; também há aqueles que buscam articular trabalhos teóricos e práticos. Todos esses modos de viabilizar o ensino não são excludentes, apenas referem-se a aspectos que os professores buscam priorizar e enfatizar na disciplina.

Embora nas últimas décadas os psicólogos educacionais tenham sofrido muitas críticas referentes à sua atuação - predominantemente direcionada para áreas clínica e psicométrica -, esta última não ocupa mais o lugar de destaque dentro da área da Educação nos cursos de Psicologia em Belo Horizonte. Dos vinte e três professores entrevistados, nenhum mencionou a psicometria como conhecimento fundamental para o psicólogo atuar no contexto educacional/ escolar; apenas um deles chamou a atenção para o fato de que a formação em Psicologia tem negligenciado a psico- metria e observou que esta área não se resume a uma mera aplicação de testes. Segundo ele, a psicometria é um campo de saber muito mais amplo, e o desconhecimento disso tanto pelos alunos quanto pelos profissionais de Psicologia tem contribuído para que esta área seja alvo de inúmeras críticas. Essa visão acerca da psicometria também é compartilhada por Vieira (2012), que observa a necessidade de o psicólogo conhecer esse campo. Ao se qualificar para uso de testes de maneira contextualizada, a autora observa que estes podem se configurar em aliados e coadjuvantes na prática cotidiana.

Os coordenadores entrevistados foram unânimes em apontar a importância de se associar pesquisa, ensino e extensão para uma formação de qualidade, não somente para o campo da Educação, mas para todas as áreas de atuação. Segundo eles, a pesquisa despertaria nos alunos o interesse pela investigação e ajudaria na construção de uma prática psicológica mais crítica e reflexiva; por sua vez, a extensão proporcionaria aos alunos a possibilidade de atuar diretamente na sociedade. Para os cursos que não possuem tradição em pesquisa, os coordenadores salientaram a importância dos trabalhos de conclusão de curso, vistos como uma das poucas oportunidades que os alunos têm para exercitar sua prática investigativa durante a graduação.

A indissociabilidade entre ensino, pesquisa e extensão como dimensão fundamental no processo formativo é defendida por estudiosos da área (Cruces, 2010; Senna \& Almeida, 2007). Para esses autores, é preciso haver um resgate urgente da pesquisa, "necessária a uma boa prática" (Gomes, 1996, p. 37), e a construção de um processo integrado entre esta, o ensino e a extensão.

Ademais, a graduação não seria somente o alvo: Marinho-Araújo e Neves (2007) salientam a necessidade de se ampliar a formação para além da graduação, numa formação continuada, o que também já vem sendo alvo de atenção por parte do Conselho Federal de Psicologia - CFP. Tendo em vista essa necessidade e a emergência de áreas específicas de atuação do psicólogo, no ano de 2000 o CFP estabeleceu normas e procedimentos necessários para conceder aos psicólogos o registro de especialista em determinados campos da Psicologia. Dentre as especialidades aprovadas pela resolução n. ${ }^{\circ}$ 014/00, três relacionam-se à área da Educação: Psicologia Escolar/Educacional, Psicopedagogia e Psicomotricidade. Embora essa resolução tenha sido substituída pela de . $^{\circ} 013 / 2007$, as especialidades relacionadas à Educação e a forma de obtenção do título de psicólogo especialista permaneceram. Assim, a partir dessas resoluções, o MEC reconhece a importância de os profissionais da psicologia manterem-se em um processo contínuo de formação.

Os dados levantados nesta pesquisa realizada em Belo Horizonte não deixam dúvidas quanto à necessidade apontada pelas autoras acima (Marinho-Araújo \& Neves, 2007). O estudo revelou a existência de apenas dois cursos de especialização na área da psicologia educacional, o que, possivelmente, diz de uma deficiência neste processo, ainda que relativa à oferta de cursos. 
Em outra perspectiva, dos 14 (catorze) professores entrevistados, cinco acreditam que a formação do psicólogo para atuar no contexto educativo/escolar tem caminhado em direção à superação das críticas de uma atuação descontextualizada; porém eles alertam que muito ainda precisa ser feito. Durante a entrevista, uma professora afirmou que sempre trabalha nas disciplinas referentes à Psicologia da Educação com uma perspectiva crítica, voltada para as demandas sociais e políticas públicas educacionais. Nessa mesma perspectiva, outro professor alegou que hoje a própria demanda modificou-se e a escola já não quer um psicólogo para fazer atendimento clínico, mas necessita de um profissional para fazer um trabalho mais coletivo e integrado.

Tendo em vista as modificações na atuação dos psicólogos no contexto educacional brasileiro, Martínez (2007) apresenta as diversas possibilidades de ação que o profissional de psicologia pode desenvolver dentro das escolas. Entre elas, a autora destaca as funções emergentes, que incluem: participação na elaboração e operacionalização das propostas pedagógicas; caracterização da população estudantil; implementação de políticas públicas - entre outras. Todas essas propostas vão ao encontro de uma atuação psicológica contextualizada e comprometida com as demandas coletivas.

Dentre as melhorias fundamentais à formação do psicólogo para atuar no contexto educacional brasileiro, quatro dos catorze professores entrevistados em nossa pesquisa salientaram a necessidade de se articular de modo mais eficaz o tripé ensino-pesquisa-extensão durante a graduação. Três ressaltaram a importância de estabelecer diálogos com outras áreas do conhecimento, visto que o meio educacional/ escolar exige que o psicólogo atue conjuntamente com outros profissionais da Educação e outros três professores falaram da necessidade de ampliar as ofertas de estágio na área.

Ainda quanto à questão das melhorias, três dos entrevistados destacaram a importância de o psicólogo educacional ter sua identidade profissional bem definida, pois, segundo ele, esta é uma das condições essenciais para o trabalho em equipes multiprofissionais.

\section{Considerações finais}

A pesquisa veio confirmar alguns fatos comprovados por outros estudos e até mesmo discutidos pela literatura específica do campo da Psicologia Educacional/Escolar. Nessa perspectiva, destacam-se as mudanças estruturais já perceptíveis nas concepções dos cursos, impulsionadas por debates intensos e, sobretudo, pela implementação das Diretrizes Curriculares Nacionais para os cursos de graduação em Psicologia de 2004.

Ficaram explícitas as dificuldades que as instituições vêm enfrentando para operacionalizar as orientações propostas nas Diretrizes. A oferta das ênfases pelos cursos é uma dessas questões, possibilitando várias reflexões. Ao proporem uma formação organizada com base num núcleo comum que apresente os conteúdos básicos necessários para atuação profissional, aliada a uma formação que contemple as especificidades do campo, as Diretrizes traçam orientações que visam garantir ao aluno e futuro psicólogo o desenvolvimento de competências e qualificações que o habilitem a articular seus conhecimentos de forma a utilizá-los nos mais diversos contextos. Há uma orientação também para que as ênfases não se configurem em especializações.

Retomando-se a hipótese investigativa já apresentada neste trabalho, pode-se afirmar que essa hipótese foi confirmada. Com base no fato de que formação e atuação são dimensões intrinsecamente articuladas e indissociáveis, tem-se que a oferta das ênfases pelos cursos estudados é uma questão que possibilita várias reflexões. Ao não contemplarem o campo da Educação como uma ênfase, não estariam esses cursos trabalhando no sentido de continuidade da tão criticada fragilidade na formação para a área?

No campo das permanências, ficou evidenciado que os cursos ainda apresentam lacunas no processo formativo: há necessidade de maior articulação entre conteúdos teóricos e práticos, e os campos de estágio na área educacional necessitam de ampliação - o que foi reivindicado como melhoria pelos entrevistados. A recorrente problemática referente à falta de definição da identidade do psicólogo que atua no contexto educacional - apontada como um fator necessário para sua futura inserção no mercado de trabalho - também se evidenciou nessa pesquisa como um fator a ser observado no processo formativo.

No campo dos desafios, a pesquisa indicou mudanças necessárias para uma formação de qualidade na área em estudo. Dialogar com outras áreas do conhecimento é uma necessidade, visto que o âmbito educacional é complexo e multifacetado, exigindo do psicólogo atuação em parceria com outros profissionais da Educação. Nessa perspectiva, a transdisciplinaridade impõe-se como imperativo aos cursos de graduação e poderá favorecer ao futuro psicólogo não apenas transitar com desenvoltura entre diversas áreas de atuação, mas principalmente ajudá-lo a ter uma visão contextualizada dos fenômenos psicológicos. Outro desafio que se impõe para os cursos e - claro - para o campo da psicologia educacional/escolar é viabilizar a necessária indissociabilidade entre ensino, pesquisa e extensão, fundamental para uma formação de qualidade.

Demarca-se, neste contexto, um momento especial na realidade brasileira, onde a proposta central é a de uma educação para todos. O psicólogo hoje é solicitado a intervir em contextos educativos/escolares plurais. Essa demanda exige um profissional capaz de lidar com sujeitos também culturalmente plurais e ao mesmo tempo singulares em sua humanidade. Para responder a essas atuais exigências com qualidade, é preciso haver um preparo que comece na graduação e continue como um modelo de formação continuada, capaz de qualificar o psicólogo para atuar na complexidade dos contextos educativos/escolares.

Revelando um processo de formação em mudança, a pesquisa indicou também que muitas respostas sobre os rumos desse processo ainda estão por vir. Fica no ar a pergunta se realmente essa formação garantirá ao psicólogo 
condições de atuar de forma consistente nessa realidade que se apresenta.

\section{Referências}

Asbahr, F. S. F., Martins, E., \& Mazzolini, B. P. M. (2011). Psicologia, formação de psicólogos e a escola: desafios contemporâneos. Psicologia em Estudo, 16(1). Recuperado: 19 Out 2011. Disponível: http://www.scielo.br/scielo.php?script=sci_arttex t\&pid=S141373722011000100019\&Ing=en\&nrm=iso.

Bardin, L. (1979). Análise de Conteúdo. Lisboa: Edições 70.

Bastos, A. V. B, Gondim, S. M. G. (2010). O trabalho do psicólogo no Brasil. Porto Alegre: Artmed.

Botomé, S. P. (2007). Onde falta melhorar a pesquisa em Psicologia no Brasil, sob a ótica de Carolina Martuscelli Bori. Psicologia: Teoria e Pesquisa, 23, 29-40.

Brasileiro, T. A., Souza, M. P. R. (2010). Psicologia, diretrizes curriculares e processos educativos na Amazônia: um estudo da formação de psicólogos. Psicologia Escolar e Educacional (Impresso), 14(1). Recuperado: 24 out 2011. Disponivel: http:// www.scielo.br/scielo.php?script=sci_arttext\&pid=S1413$85572010000100012 \&$ lng=en\&nrm=iso.

Campos, H. R. (Org.). (2007). Formação em psicologia escolar: realidades e perspectivas. Campinas, SP: Alínea.

Correia, M. F. B., Lima, A. P. B., Araujo, C. R. (2001). As Contribuições da Psicologia Cognitiva e a Atuação do Psicólogo no Contexto Escolar. Psicologia: Reflexão e Crítica, 14(3). Recuperado: 19 out 2011. Disponível: http://www.scielo.br/scielo.php?script=sci_ arttext\&pid=S0102-79722001000300010\&lng=en\&nrm=iso.

Cruces, A. V. V. (2010). Professores e pesquisadores em psicologia escolar: desafios da formação. Em Aberto, 23(83), 129-149.

Figueiredo, L. C. M. (2009). Matrizes do Pensamento Psicológico. Petrópolis, RJ: Vozes.

Franco, M. L. P. B. (2005). Análise de conteúdo. Brasília: Leiber Livros.

Gomes, W. B. (1996). Pesquisa e ensino em Psicologia: Articulações entre graduação e pós-graduação. Em: R. M. L. Carvalho (Org.), Repensando a formação do psicólogo: da informação à descoberta (pp. 33-49). Campinas, SP: Editora Alínea.

Larocca, P. (2000). O saber psicológico e a docência. Psicologia, Ciência e Profissão, 20(2), 60-65.

Marinho-Araújo, C. M. (Org.). (2009). Psicologia escolar: novos cenários e contextos de pesquisa, formação e prática. Campinas, SP: Alínea
Marinho-Araújo, C. M., \& Neves, M. M. B. J. (2007). Psicologia escolar: perspectivas e compromissos na formação continuada. Em H. R. Campos (Org.), Formação em Psicologia Escolar: realidades e perspectivas (pp. 69-87). Campinas, SP: Alínea.

Martínez, A. M. (2007). O psicólogo escolar e os processos de implantação de políticas públicas: atuação e formação. Em H. R Campos (Org.), Formação em Psicologia Escolar: realidades e perspectivas (pp. 109-133). Campinas, SP: Alínea.

Meira, M. E. M, \& Antunes, M. A. (Orgs.). (2003). Psicologia escolar: práticas críticas. São Paulo: Casa do Psicólogo.

Parecer CNE/CES 0062. (2004, 09 de fevereiro). Fixa as Diretrizes Curriculares Nacionais para os cursos de graduação em Psicologia. Ministério da Educação. Recuperado: 01 nov 2011. Disponivel: http://www.portal.mec.gov.br/cne/arquivos/pdf/2003/ pces062_03.pdf.

Patto, M. H. S. (1984). Psicologia e ideologia: uma introdução crítica à Psicologia Escolar. São Paulo: T.A Queiroz Editores.

Patto, M. H. S. (1991). A produção do fracasso escolar. São Paulo: T.A Queiroz Editores.

Resolução CFP No 013. (2007). Institui a Consolidação das Resoluções relativas ao Título Profissional de Especialista em Psicologia e dispõe sobre normas e procedimentos para seu registro. Recuperado: 01 jul 2011. Disponível: http://www. psicologia-online.org.br.

Resolução CFP No 014. (2000). Institui o título de Especialista em Psicologia e dispõe sobre normas e procedimentos para seu registro. Conselho Federal de Psicologia. Recuperado: 01 jul 2011. Disponível: http://www.psicologia-online.org.br.

Resolução $n^{\circ}$. 8. (2004, 07 de maio). Institui as Diretrizes Curriculares Nacionais para os cursos de graduação em Psicologia. Ministério da Educação. Recuperado: 01 nov 2011. Disponível: http://www. portal.mec.gov.br/cne/arquivos/pdf/rces08_04.pdf.

Rodrigues, M. C, Itaborahy, C. Z, Pereira, M. D., \& GONÇALVES, T. M. C. (2008). Prevenção e promoção de saúde na escola: concepções e práticas de psicólogos escolares. Gerais: Revista Interinstitucional de Psicologia, 1(1), 67-78.

Santos, A. (2008). Complexidade e transdisciplinaridade em educação: cinco princípios para resgatar o elo perdido. Revista Brasileira de Educação, 13(37). Recuperado: 24 out 2011. Disponível: http://www.scielo.br/scielo.php?script=sci arttext\&pid=S1413$24782008000100007 \&$ Ing=en\&nrm=iso

Senna, S. R. C. M., \& Almeida, S. F. C. (2007). Formação e atuação do psicólogo escolar da rede pública de ensino do Distrito Federal. Em A. M. Martínez (Org.), Psicologia Escolar e Compromisso Social (pp. 199-230). Campinas, SP: Alínea. 
Souza Filho, M., Oliveira, J. S. C., \& Lima, F. L. A. (2006). Como as pessoas percebem o psicólogo: um estudo exploratório. Paidéia, 16(34), 253-261.

Souza, C. S., Ribeiro, M. J., \& Silva, S. M. C. (2011). A atuação do psicólogo escolar na rede particular de ensino. Psicologia Escolar e Educacional, 15(1). Recuperado: 24 out 2011. Disponível: http://www.scielo.br/scielo.php?script=sci_arttext\&pid=S1413$85572011000100006 \&$ Ing=en\&nrm=iso.
Vieira, R. (2012). O psicólogo na educação: fazeres possíveis. São Paulo: Annablume.

Yamamoto, O. H., \& Costa, A. N. F. (2010). (Orgs.). Escritos sobre a profissão de psicólogo no Brasil. Natal: EDUFRN.

Recebido em: 25/04/2012

Reformulado em: 20/08/2012

Aprovado em: 25/10/2012

\section{Sobre as autoras}

Rita de Cássia Vieira (rita.vieira@yahoo.com.br)

Pesquisadora, psicóloga e coordenadora técnica do Laboratório de Psicologia e Educação Helena Antipoff da Faculdade de Educação da Universidade Federal de Minas Gerais (Laped/FaE/UFMG). Doutora em Educação pela UFMG.

Endereço para correspondência:

Faculdade de Educação da UFMG/DECAE/Laped/sala 1671

Av. Antonio Carlos 6627 - Campus Pampulha

CEP 31270-901 - B.H. - Minas Gerais

Ellen Rose Fernandes Figueiredo (rose.ellen@bol.com.br)

Graduanda em Psicologia pela Universidade Federal de Minas Gerais, membro do Laboratório de Psicologia e Educação Helena Antipoff (Laped/FaE/UFMG). Bolsista Fapemig de Iniciação Científica.

Endereço: Rua R, no. 70 - Bairro Tirol - Contagem/MG

Laís Gonçalves de Souza (lais.gsouza@hotmail.com)

Graduanda em Psicologia pela UFMG, membro do Laboratório de Psicologia e Educação Helena Antipoff(Laped/FaE/UFMG). Bolsista Fapemig de Iniciação Científica.

Endereço: Av.Judith Naves de Lima n.243, ap.C, Funcionários, Contagem/MG,

Marina Castana Fenner (marina_fenner@yahoo.com.br)

Graduanda em Psicologia pela UFM, membro do Laboratório de Psicologia e Educação Helena Antipoff(Laped/FaE/UFMG). Bolsista Fapemig de Iniciação Científica.

Endereço: R.Ordália, 174 Glória30870-300 Belo Horizonte/Minas Gerais

Agradecemos o apoio financeiro da FAPEMIG (Fundação de Amparo a Pesquisa do Estado de Minas Gerais) para a realização desta pesquisa. 